Eggo Müller

\title{
VAN INTERACTIVITEIT NAAR PARTICIPATIE
}

Communicatie, mediaal bemiddeld of in directe vorm, is in de geschiedenis van de filosofie, de media en de culturele en sociale wetenschappen onlosmakelijk verbonden met het idee van interactiviteit. Ideale communicatie is interactief in die zin dat alle deelnemers daaraan gelijkwaardig zijn en vrij van welke vorm van macht of dwang dan ook; als gelijken kunnen zij bijdragen aan communicatieve uitwisseling en toenadering. Zo gaat het bijvoorbeeld in de hermeneutiek van Hans-Georg Gadamer om het 'verstaan' van een ander, dat tot stand komt wanneer er sprake is van een versmelting van de horizonnen van tekst of auteur en lezer. ${ }^{I}$ Een voorbeeld uit de sociale wetenschap is het symbolisch interactionisme van Herbert Blumer, ${ }^{2}$ George Herbert Mead of Erving Goffman, dat de gezamenlijke constructie van realiteit als gevolg van sociale interactie en communicatie centraal stelt. ${ }^{3}$ En een voorbeeld uit de filosofie is de door Jürgen Habermas beschreven ethica van het discours: hier worden 'communicatieve handelingen' als een specifieke vorm van interactie beschouwd waarbij subjecten in een situatie vrij van maatschappelijke en sociale dwang tot wederzijds begrip komen om, gebaseerd daarop, hun handelingen op elkaar en op een rationele manier af te kunnen stemmen. 4

Deze wetenschappelijke modellen uit uiteenlopende contexten zijn maar drie voorbeelden van de kenmerkende manier waarop in het moderne denken een verband wordt gelegd tussen communicatie, interactie en wederzijds begrijpen. Menige utopie van nieuwe mediatechnologieën die de fragmentering van het menselijk bestaan zullen beïnvloeden en een democratische participatie aan de samenleving zullen garanderen, ${ }^{5}$ borduurt voort op een dergelijke veronderstelling van communicatie als ideale vorm van interactie. En omgekeerd: van interactie als voorwaarde voor ideale communicatie. Uit de teksten van De Vries, Post en Müller in dit nummer van het Tijdschrift voor Mediageschiedenis komt dit nadrukkelijk naar voren. Tegelijkertijd wijzen deze drie teksten erop, dat dit maar een utopie is, wellicht, zoals De Vries veronderstelt, met sturend karakter bij de ontwikkeling, maar zeker bij de marketing van nieuwe media en communicatietechnologieën. En toch betekent dit niet per se dat telkens een specifieke vorm van de maatschappelijke institutionalisering van een nieuwe technologie of een nieuw medium - zoals door Baaren voor interactieve televisie beschreven - inderdaad tot de verwezenlijking van 
utopische visies bijdraagt. Integendeel: zoals de Amerikaanse communicatiewetenschapper en socioloog James Beniger in een mediahistorisch onderzoek heeft aangetoond, gaat de ontwikkeling van nieuwe informatietechnologieën gepaard met vraagstukken inzake meer efficiënte manieren van controle en sturing met het oog op de uitbreiding van productie en markten. ${ }^{6}$ Inderdaad wordt in de context van de online-economie het einde van de massa- en consumptiemaatschappij afgekondigd en de komst van de 'prosumer' gevierd, namelijk van een consument die zelf de middelen tot productie en distributie van goederen en diensten in handen heeft.7 Toch wordt in dit verband vaak een buitengewoon beperkt begrip van 'productie' gebezigd. Zo definieert de Amerikaanse econoom Don Tapscott de 'prosumer' in The Digital Economy als volgt:

'Every consumer on the information highway becomes a producer by creating and sending a message to a colleague, contributing to a bulletin-board discussion group, altering the end of a movie, test driving a virtual car, or visualizing the brain of a patient across the country.'

Wat Tapscott hier beschrijft, zou men ook het IKEA-principe kunnen noemen: een economisch principe waar de producent bepaalde taken uitbesteedt aan de consument; deze krijgt daardoor een bepaalde, zeer beperkte rol in het productie- of communicatieproces toegewezen. Uit een mediaspecifiek voorbeeld dat Tapscott bespreekt, wordt duidelijk dat aan zijn visie van de 'prosumer' vooral het concept van customizing ten grondslag ligt:

'In the new economy the gap between consumers and producers blurs. (...) In the old economy, viewers watched the evening network news. In the new economy, a television viewer will design a customized news broadcast by highlighting the top ten topics of interest and specifying preferred news sources, editorial commentators, and graphic styles. Moreover, that same viewer will be able to watch that broadcast whenever time permits or the need arises'. 9

De zeer beperkte invloed van de consument op het product, de distributie en de receptie daarvan betekent wel een verandering van de relatie tussen producent en consument. Toch volgt daaruit niet dat de verschillen tussen beide posities in communicatieprocessen helemaal vervagen. De traditionele positie en relatie van producent en recipiënt wordt veeleer geherdefinieerd volgens de belangen van een economisch systeem dat zich steeds meer op specifieker doelgroepen richt dan op een massamarkt. Daarbij spelen interactieve media - communicatietechnologieën met een retourkanaal - een uitermate belangrijke rol. Zowel voor de uitwisseling van informatie en het creëren van meer gespecialiseerde netwerken als voor het verkrijgen van toegang tot de individuele consument of 'prosumer'. ${ }^{\text {Io }}$ 
Tegen de achtergrond van de twee genoemde dimensies van interactiviteit - enerzijds de utopische visie en anderzijds het economisch-technologisch concept ter herdefiniëring van de traditionele scheiding tussen productie en consumptie in een massasamenleving - kan men stellen dat het begrip van interactiviteit twee verschillende tijdsbestekken kent. Elk is daarbij gericht op een ander doel. In de gedaante van een utopische visie richt zich 'interactiviteit' als concept kritisch tegen de historische institutionalisering van bepaalde media- en communicatietechnologieën waarin het technologische potentieel om aan een democratische vorm van communicatie bij te dragen, niet werkelijk is ontwikkeld. In de gedaante van een economisch-technologisch concept richten interactieve technologieën en toepassingen zich op de pragmatische ontwikkeling van toekomstige systemen ter terugkoppeling, sturing en controle van informatie en processen van informatie-uitwisseling.

Het besef dat het concept 'interactiviteit' twee verschillende tijdsspannen bevat en afhankelijk daarvan duidelijk uiteenlopende betekenissen heeft, zou je als triviaal kunnen afdoen. Elke ingrijpende transformatie of omwenteling van bestaande institutionele, technische, sociale of culturele relaties betekent per definitie dat er tegelijkertijd tradities worden afgebroken (wat in een utopische visie als 'bevrijding' wordt beschreven) en nieuwe structuren worden ontwikkeld (wat in een dystopisch perspectief over het algemeen als toename van uitbuiting en controle wordt bekritiseerd). Toch kan dit besef helpen om in het publieke en wetenschappelijke debat over Nieuwe Media helderder te redeneren. De vraag is niet of een nieuwe technologie of nieuw medium interactief is, de vraag moet luidden: wat betekent de institutionalisering van een specifieke vorm van interactiviteit voor de herdefiniëring van de relatie tussen producenten en consumenten, voor de toegankelijkheid van media en voor de democratisering van het publieke discours. In wezen gaat het om de vraag of nieuwe media in interactieve toepassingen en diensten mogelijkheden tot politieke, sociale en culturele participatie werkelijk verruimen. Vergeleken met niet-interactieve vormen van communicatie introduceren interactieve technologieën wel een nieuwe kwaliteit (in de zin van een nieuwe karakteristiek) van gemedieerde communicatie, maar dit betekent niet dat daarmee ook per definitie een meer waardevolle vorm van participatie gepaard gaat.

Uit de geschiedenis van media en communicatie blijkt dat het begrip van een medium of een communicatievorm telkens is bepaald door andere media en communicatievormen. In die zin dat de specificiteit van een medium of communicatievorm altijd in vergelijking met andere media en communicatievormen wordt ervaren. Zo werd de bijzondere kwaliteit die we vandaag de dag aan directe, interpersoonlijke communicatie toekennen, historisch pas 'voelbaar' en in het discours bespreekbaar toen gemedieerde massacommunicatie tot een bepalende maatschappelijke vorm van communicatie was uitgegroeid. Daarom zal die toename aan interactieve mediatechnologieën en participatiemogelijkheden ook tot een nieuw begrip van de kwaliteit van massamedia- en 
massacommunicatie kunnen of eigenlijk moeten leiden. Waar er sprake is van interactieve media en communicatie, geldt wat de Oostenrijks-Amerikaanse psychotherapeut en communicatiewetenschapper Paul Watzlawik over communicatie heeft gesteld: ${ }^{\text {II }}$ het is namelijk, wanneer er sprake is van interactiviteit, onmogelijk om niet te 'interageren'. De kwaliteit van traditionele massamedia zou daarom kunnen zijn, dat je in plaats van te moeten interageren, gewoon mag kijken en luisteren naar wat opgeleide professionals hebben gecreëerd.

Met andere woorden: nadenken over interactiviteit in de mediahistorische context kan tot nieuwe inzichten leiden wanneer niet bij voorbaat verondersteld wordt dat interactieve media in vergelijking met gemedieerde massacommunicatie of directe persoonlijke communicatie per definitie een betere vorm van communicatie betekenen. De in dit themanummer verzamelde bijdragen zijn voorbeelden van een dergelijke, meer gedifferentieerde en in zekere zin empirisch-historische benadering van interactiviteit en interactieve toepassingen. Als een ensemble van teksten willen zij aanzetten tot een kritische kijk op het concept van interactiviteit - in de ontwikkeling van (nieuwe) media en in het media- en communicatiewetenschappelijk onderzoek.

I Hans-Georg Gadamer, Wahrheit und Methode. Grundzüge einer philosophischen Hermeneutik. Tübingen I960.

2 Herbert Blumer, Symbolic interactionism: perspective and method. Berkeley I969.

3 Zie als algemene inleiding Heinz Abels, Interaktion, Identität, Repräsentation. Kleine Einführung in interpretative Theorien der Soziologie. Wiesbaden 2004.

4 Jürgen Habermas, Theorie des kommunikativen Handelns, Bd. I: Handlungsrationalität und gesellschaftliche Rationalisierung. Frankfurt a.M. I981, p. I28.

5 Zie hiervoor het hoofstuk 'Discourses of progress and utopia' in de recent verschenen dissertatie van Imar de Vries: Tantalisingly close: An archaeology of communication desires in discourses of mobile wireless media. Utrecht 2008, pp. 2I-59.

6 James R. Beniger, The control revolution: technological and economic origins of the information society. Cambridge i986.

7 Zie Don Tapscott, The digital economy: promise and perils in the age of networked intelligence. New York [etc.] I996, p. $62 \mathrm{f}$.

8 Idem.

9 Idem.

Io Zie voor een fundamentele kritiek op de nieuwe online-economie: Mark Andrejevic, Reality-TV: the work of being watched. Lanham 2003.

II Paul Watzlawik, Janet Beavin Bavelas \& Donald D. Jackson, Pragmatics of human communication: a study of interactional patterns, pathologies, and paradoxes. New York I967, p. 48ff. 